\title{
Identification of Service and Pricing Factors at a Padang Restaurant
}

\author{
Istiadi \\ Office Administration and Secretary Laboratory, Vocational Education Program, Universitas Indonesia \\ *Email: istiadi_soenarto@yahoo.com
}

\begin{abstract}
Campus restaurants offer benefits to students who live on campus, live with their parents, or live in boarding houses, and they present opportunities to other businesses in the area. However, running a business as a food-service entrepreneur can be challenging because one needs an understanding of the restaurant business and an appreciation of the value of menu innovation. Small Business Trends (2011) reported the following: "The most appealing elements of business (at least for me right now) are innovation, connection, and courtesy." Therefore, various strategies related to service and pricing need to be determined to run a restaurant. A small business entrepreneur is defined as an individual who establishes and manages a business for the principal purpose of profit and growth (Carland et al., 1984; Yallapragada and Bhuiyan, 2011). This study describes how Padang restaurant entrepreneurs near the Universitas Indonesia campus and the area surrounding another university near Depok City implement service and price policies for a clientele of students on limited budgets.
\end{abstract}

Keywords: restaurant, service and pricing policy, entrepreneurship, campus

\section{Introduction}

Small businesses generate income for families and create jobs. Ayyagari (2011) (cited in Kachlami and Yazdanfar, 2016) indicates that approximately 95\% of all enterprises in the world (representing $60 \%$ of all private employment) are small and medium-sized enterprises (SMEs) with fewer than 250 employees and annual turnovers of $<50$ million euros (OECD, 2004). Although employment incomes from SMEs are far below those of large companies, small businesses play a major role in the health of the economy. Although major players appear to dominate the marketplace, many businesses are managed by individual owner/operators (Jogaratnam, 2017). The Padang restaurant is one type of self-managed restaurant that has proved popular with the people of Indonesia. Success for a Padang restaurant means providing a pleasant service for its customers, most of whom are students. Therefore, innovation in providing service to customers is essential. Product innovation reflects a change in the final product or service offered by companies, whereas the innovation process represents a change in the way the companies produce products and services (Killa, 2018).

In the restaurant business today, it is no longer enough to be "close to your customer" via attentive, quality service alone (Arora et al., 2016). This means that Padang restaurant managers, who typically face the threat of competition from Tegal restaurants, must embrace a comprehensive strategy to ensure that customers remain loyal to the business. Although satisfying customers can be reduced to rational business decisions, loyalty is not a rational evaluation but is the result of a variety of less tangible and often unconsciously perceived factors (Kiseleva et al., 2016).

\section{Literature Review}

Successful small businesses do not separate their service strategy from their pricing strategy, particularly in a university campus environment. Service is the key to retaining customers, but price is no less important in determining the success or failure of a Padang restaurant. Almost any business can improve its pricing performance, provided that it approaches the task in a structured way (Hinterhuber and Liozu, 2012). A greater understanding of pricing can be an effective competitive tool (Naipaul, 2002). Demand-based pricing is largely absent in the restaurant industry because many operators are concerned that customers will consider such practices unfair and unacceptable (Kimes et al., 2002).

\section{Methodology}

This research was conducted using a qualitative approach, and some data were obtained by using questionnaires and interviews. In this study, student data collectors met directly with the owners and servants of 13 Padang restaurants near Vocational Program B, University of Indonesia. In qualitative research, the concept needs to be established first before performing data collection. 


\section{Results and Discussion}

Small businesses, particularly restaurants, tend to be affected less by a global crisis (Kaya, 2018). Considering that service and price occupy leading roles in restaurant marketing, this study focuses on the aspects related to service provision in a Padang restaurant.

\section{Service Factors}

The service factors include the following:

$>$ Condition of the place of business

$>$ Number of employees and speed of service

$>$ Hours of business

$>$ Opening time

$>$ Food quality

\section{Condition and status of the place of business}

Campus Padang restaurants are typically $4 \mathrm{~m} \times 5 \mathrm{~m}$ in size, and some are even smaller. Most are considered relatively clean, and most $(92.3 \%)$ are rented rather than owned by the business itself (Figure 1).

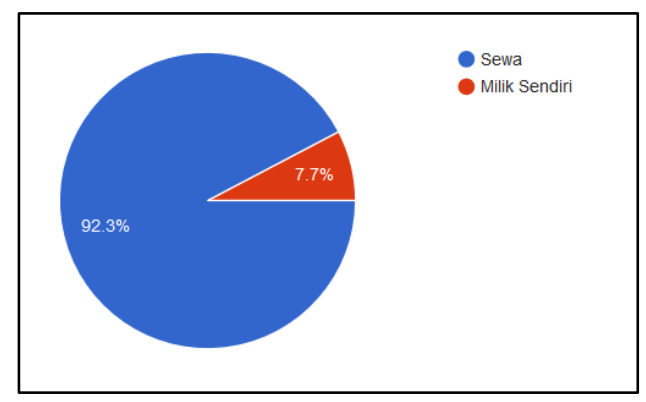

Fig. 1. Business location status: owned vs. rented

The rental prices of each restaurant vary. The most expensive rental rates are associated with strategic locations that offer easy access to customers on the Margonda roadside and are near Campus Vokasi Universitas Indonesia Program. Many restaurant owners are usually not in a position to purchase properties in such valuable locations; therefore, they are forced to rent. However, $7.7 \%$ of restaurateur respondents own their establishments, which were originally run by parents who could afford ownership.

\section{Number of employees - the speed of service}

The number of employees will affect the speed of servicing consumers and the overall quality of service. Figure 2 shows the number of employees when the 13 Padang restaurants first opened.

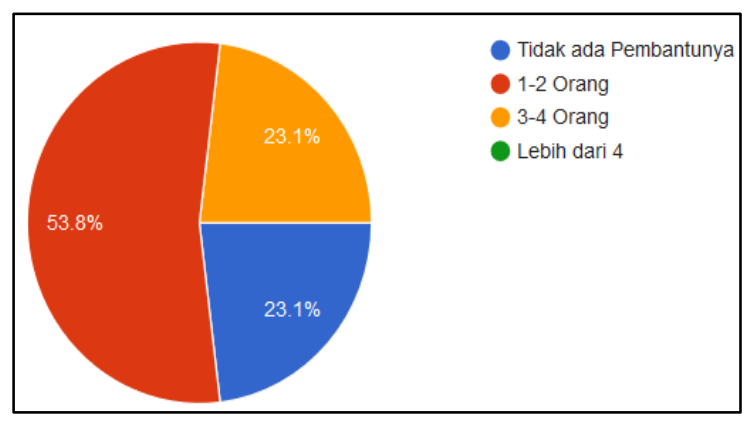

Fig. 2. Number of employees at the first opening

The number of employees on payroll when the 13 Padang restaurants first opened varies. However, 11 respondents $(53.8 \%)$ stated that they were initially assisted by only 1 or 2 workers, and these workers are typically related to the owner (e.g., a husband or sibling) rather than people recruited from the larger community. One respondent was assisted by three or four people, and one respondent had no staff help. Judging from the results from the opening of his business, the latter owner focused on building his business first before hiring staff (Figure 3). 


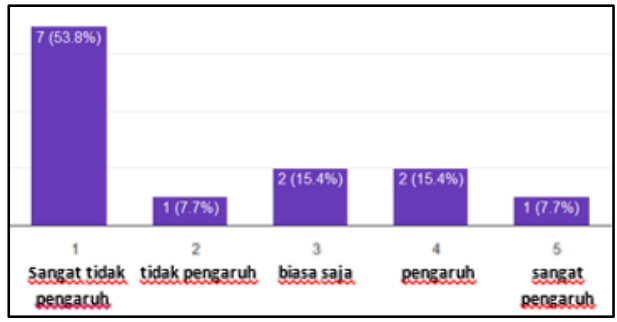

Fig. 3. Influence of assistants/employees in daily cooking activities

As much as $53.8 \%$ of respondents assumed that the presence of an assistant or employee was not essential because cooking activities were performed only by the owner of the restaurant to ensure consistent quality.

\section{Open weekdays}

The success of food businesses in campus environments is strongly related to the level of consistency when serving customers who are mostly students. Some campus Padang restaurants are open seven days a week (Figure 4).

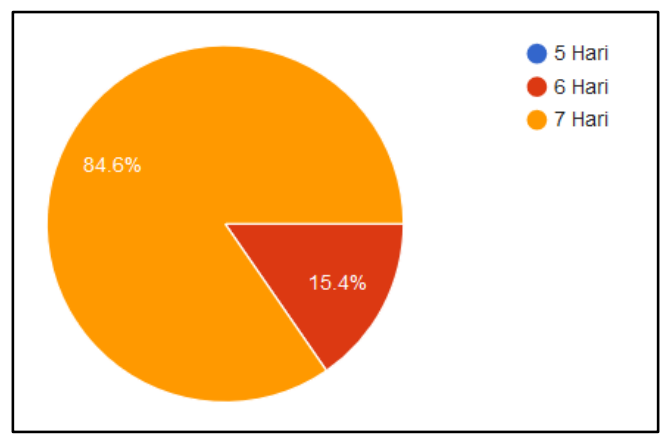

Fig. 4. Open dinner schedule in a week

The opening schedule of a Padang restaurant is not limited by the owner (Figure 4). As many as $84.6 \%$ of Padang restaurants are open every day of the week, and the remaining $15.4 \%$ are open six days a week. The majority of Padang restaurants do not open on Sundays because potential visitors spend Sundays at home with their families.

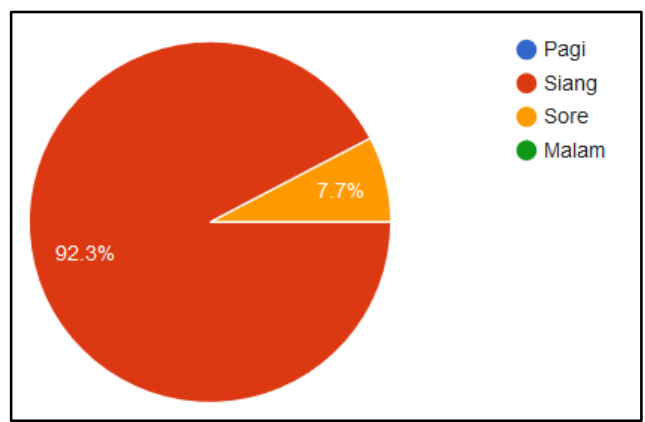

Fig. 5. Times of day when buyers frequently visited restaurants

Respondents stated that most customer visits occur at noon and in the afternoon (Figure 5), with $92.3 \%$ of visits recorded at a time of rest or lunch. The restaurant is usually only crowded until the afternoon. Therefore, it can be concluded that many potential customers have returned home by evening. Most respondents also stated that the restaurant was closed at night, and side dishes were no longer available.

\section{Opening hours of a Rumah Makan Padang}

The opening hours of Padang restaurants differ, with the majority (61.5\%) opening at 9:00 or 10:00 WIB. Restaurants tend to be crowded from 11:00 to 12:00, when dishes are more likely to be hot and more delicious. 
However, $30.8 \%$ of restaurants open at 7:00 to 8:00 a.m., when most visitors are interested in breakfast (Figure $6)$.

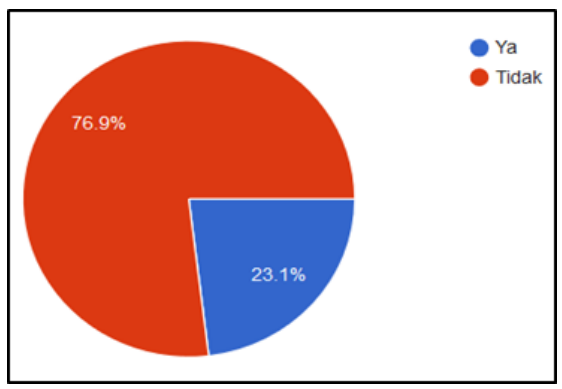

Fig. 6. Opening hours

Effect of helpers/employees in serving everyday buyers

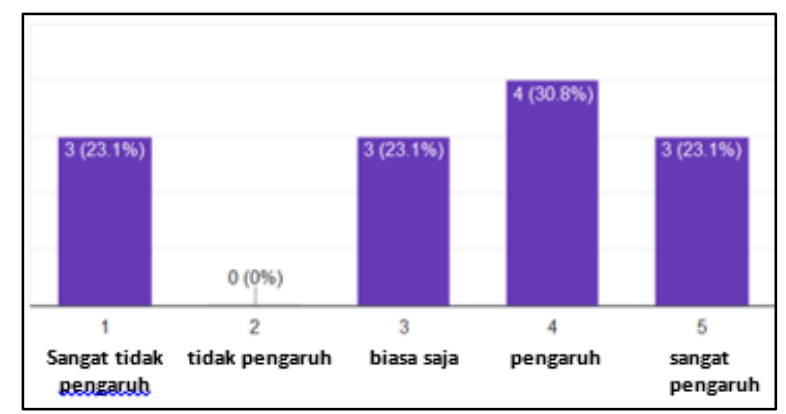

Fig. 7. Effect of helpers/employees in serving everyday buyers

Almost a third $(30.8 \%)$ of restaurant-owner respondents stated that an assistant or employee makes a significant contribution to serving customers. Helpers and employees can ease an owner's workload. If there are many customers, the owner can focus on cooking, washing dishes, cleaning tables, or serving other customers. However, some owners are not convinced of the merits of helpers and prefer to handle all tasks alone (Figure 7).

\section{Degree of influence in determining the quality of food}

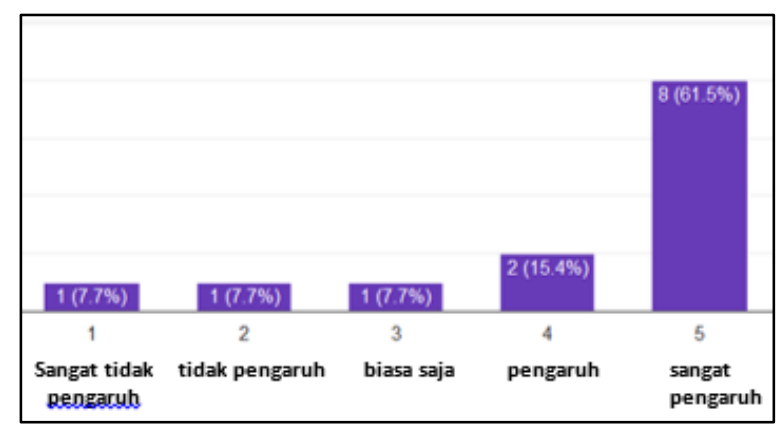

Fig. 8. Influence in determining the quality of food

The majority of restaurateurs $(61.5 \%)$ reported that supplying high-quality food is the primary method of attracting customers (Figure 8).

\section{Factors related to pricing policy}

The factors related to price include the following:

$>$ Effect of profits earned on tomorrow's sales

$>$ Dependence on a bank

$>$ Sales inventory 


\section{Effects of profit on tomorrow's sales}

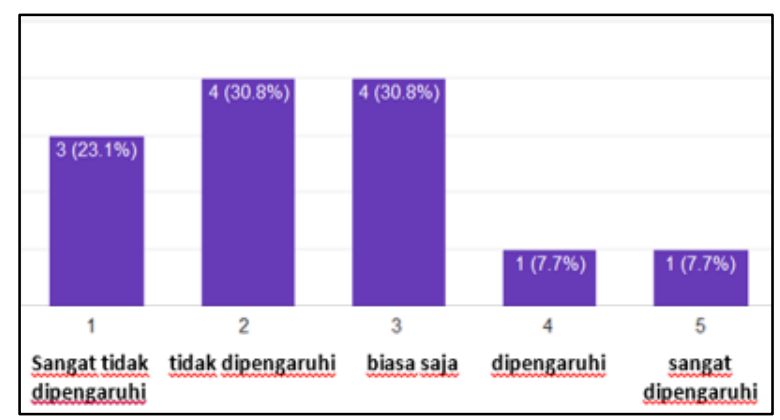

Fig. 9. How much of today's profit will be set aside for tomorrow?

Figure 9 shows that restaurant owners believe that daily profit does not necessarily affect tomorrow's sales, i.e., restaurant owners do not rely on the certainty of profit every day. The owners separate or plan their finances on a daily basis or rerun the money to trade for the next day. An owner must be able to manage finances. On the basis of the benefits incurred per day, owners usually prefer to save. Therefore, most owners do not dare assign a high price to each portion of food for fear of being undercut by other restaurants.

\section{Dependence on banks on a day-to-day business}

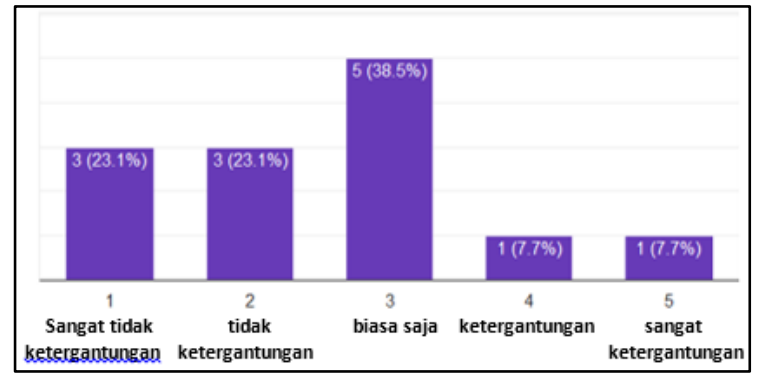

Fig. 10 Dependence on banks on a day-to-day business

More than a third $(38.5 \%)$ of Padang restaurant owners reported that they do not feel dependent on banks every day. Banks are only used to save money. However, the money is required for shopping to avoid having to return to the bank every day. Only a few of these entrepreneurs are dependent on banks on a daily basis. Therefore, they can be considered an entrepreneurial group that seeks to bid on the standard price of the campus market (Figure 10).

\section{Food inventory}

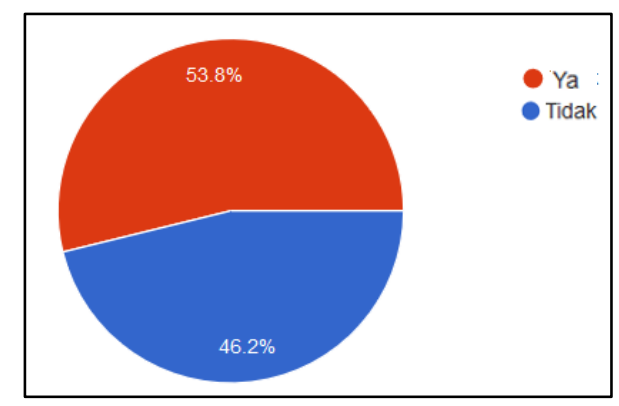

Fig. 11. Selling

Figure 11 shows that more than half $(53.8 \%)$ of restaurant respondents indicated that the food inventory of Padang restaurants is sold out every day. However, $46.2 \%$ of restaurant respondents reported that they do not run out of food on a daily basis. The number of customers determines whether the daily food supply is exhausted. At the same time, the quality of food (tasty/not tasty) can also affect the visitor rate. When food inventory is sold out, it indicates that the food is of high quality. However, when the food inventory is not 
depleted, it does not necessarily mean that the food quality is low; one reason for this situation is that only a few people visited the restaurant.

Both good service and reasonable prices contribute to the success of a Padang restaurant, and customers can be sensitive to prices in a campus marketing environment, which includes competition from wartegs (food stalls) and other restaurants. However, campus Padang restaurants are not more expensive than noncampus Padang restaurants. The price difference between a campus Padang restaurant and an outside campus restaurant ranges from IDR 3,000 to IDR 5,000.

\section{Conclusion}

This study on campus Padang restaurants produced several conclusions. First, the majority of owners state that today's profits have no substantial effect on tomorrow's sales. This is understandable because owners usually have enough money for the next business day. Regarding service strategy, the majority of Padang restaurants open at 9:00 or 10:00 a.m. This is usually based on the fact that a normal freshman student eats lunch at a restaurant but eats breakfast at home or elsewhere. The majority of Padang restaurants are open seven days a week. Second, the quality of the food and menu will be highly scrutinized by consumers. Therefore, owners need to maintain high-quality dishes. In many cases, the majority of the food is made by the owner. Third, Padang restaurants use low or medium pricing when they operate in a campus environment. However, when they operate in other areas, they use normal pricing, which is comparatively expensive for students.

\section{Acknowledgments}

I would like to thank the director of the Vacational Educational Program of Universitas Indonesia, who challenged me to write this paper. I would also like to thanks all Padang restaurant entrepreneurs who participated in this research.

\section{References}

Arora, R., \& Singer, J. (spring-summer 2006). Cognitive and affective service marketing strategies for fine dining restaurant managers. Journal of Small Business Strategy; Peoria, 17, Ist. 1, 51-61

Hinterhuber, A., \& Liozu, S. (2012). Is it time to rethink your pricing strategy? MIT Sloan Management Review, 53(4), 69-77.

Jogaratnam, G. (2017). How organizational culture influences market orientation and business performance in the restaurant industry. Journal of Hospitality and Tourism Management, 31, 211-219.

Kachlami, H., \& Yazdanfar, D. (2016). Determinants of SME growth. Management Research Review, 39(9), 966-986.

Kaya, H. D. (2018). The impact of the global crisis on entrepreneurial activity. Journal of Applied Economic Sciences, 12(8, winter), 2179-2189

Killa, M. (2018). A study on product innovation portfolio and customer value creation: Bridging entrepreneurial risk-taking orientation and marketing performance. ASEAN Marketing Journal, 9(2).

Kimes, S. E., \& Wirtz, J. (2002). Perceived fairness of demand-based pricing for restaurants. Cornell Hotel and Restaurant Administration Quarterly, 43(1), 31-37.

Kiseleva, E. M., Nekrasova, M. L., Mayorova, M. A., Rudenko, M. N., \& Kankhva, V. S. (2016). The theory and practice of customer loyalty management and customer focus in the enterprise activity. International Review of Management and Marketing, 6(6)

Naipaul, S. (2002). Psychological pricing strategies and consumers response behavior: An empirical investigation in the restaurant industry (Order No. 3039507). Available from ABI/INFORM Collection. Progr.Quest Dissertations \& Theses Global: Business. 305560808.

Small business trends: How attractive is your business? (2011). Chatham, UK: Newstex.

Yallapragada, R. R., \& Bhuiyan, M. (2011). Small business entrepreneurships in the united states. Journal of Applied Business Research, 27(6), 117-122. doi: 10.19030/jabr.v27i6.6470. 